\title{
Aspectos históricos da neuropsicologia: subsídios para a formação de educadores
}

\section{Historical aspects of the neuropsychology: a contribution to the educators formation}

\author{
Marta Pinheiro*
}

\begin{abstract}
RESUMO
A neuropsicologia é uma ciência do século XX, mas as raízes da sua história remontam a Antigüidade. O objetivo deste estudo é discutir aspectos da história da neuropsicologia, desde a sua origem até o seu surgimento e estabelecimento enquanto ciência, com o objetivo de fornecer subsídios a educadores interessados no estudo das dificuldades e dos distúrbios de aprendizagem. Uma teoria da aprendizagem efetiva deve levar em conta os substratos anatômicos cerebrais e os mecanismos neurofisiológicos do comportamento, pois só assim o educador poderá compreender o nãoaprender do aluno e, conseqüentemente, adotar estratégias adequadas para superá-lo.

Palavras-chave: neurociência cognitiva, neuropsicologia cognitiva, história da ciência.
\end{abstract}

\begin{abstract}
The neuropsychology is a science of the 20 th century but we need to return to the early history to find its origins. The objective of the present review is to discuss aspects of the historical process of scientific organization of the area with the purpose to provide fundamental concepts to educators interested in the study of learning disabilities.
\end{abstract}

* Doutora em ciências (USP). Professora do Departamento de Teoria e Fundamentos da Educação da Universidade Federal do Paraná - UFPR. E-mail: ppge@ufpr.br 
An effective learning theory must consider brain and mental processes since in this only case the educator can understand why the student doesn't learn and so adopt adequated strategies to improve his cognitive rehabilitation.

Key-words: cognitive neuroscience, cognitive neuropsychology, science history.

\section{Introdução}

A neuropsicologia é uma ciência do século XX, que se desenvolveu inicialmente a partir da convergência da neurologia com a psicologia, no objetivo comum de estudar as modificações comportamentais resultantes de lesão cerebral. Atualmente, podemos situá-la numa área de interface entre as neurociências (neste caso, ela também pode ser chamada de neurociência cognitiva), e as ciências do comportamento (psicologia do desenvolvimento, psicolingüística, entre outras) entendendo que o seu enfoque central é o estudo da relação sistema nervoso, comportamento, e cognição, ou seja, o estudo das capacidades mentais mais complexas como a linguagem, a memória, e a consciência.

Entre os profissionais interessados pela neuropsicologia ressalta-se os educadores, que têm no processo ensino-aprendizagem o seu objeto de investigação. Sujeitos com perturbações na aprendizagem sempre existiram e por isso estudos sobre os fatores determinantes das dificuldades do aprendiz existem há séculos. $\mathrm{Na}$ área escolar, os comprometimentos do aluno foram inicialmente apenas vinculados a causas orgânicas, centradas no indivíduo, que passava a ser entendido como um doente ou paciente. Posteriormente, esta perspectiva somática foi abandonada e substituída pela socioeconômica que, como o nome sugere, admite apenas a influência dos fatores do meio no desenvolvimento da inteligência. Ainda, a crença de que o aprendizado ocorre na mente e esta não tem nada a ver com o corpo levou muitos educadores a acreditar que o estudo do corpo cabia apenas aos profissionais da área da saúde, ou quiçá, ao professor de educação física. Atualmente, nenhum educador sério deixa de considerar tanto os fatores biológicos quanto os ambientais no surgimento e desenvolvimento do ser, entendendo que tudo que é psicológico é também biológico. 
Assim, entende-se que tendo o educando dificuldades ou distúrbios de aprendizagem, ${ }^{1} \mathrm{o}$ conhecimento dos métodos neuropsicológicos por esses profissionais permite não apenas um diagnóstico precoce e mais exato, mas também o estabelecimento de programas de ação terapêutica e reeducativa para o aprendiz.

Este estudo, portanto, tem por objetivo discutir aspectos históricos da neuropsicologia, como contribuição à formação de profissionais da educação.

Antes de iniciar a discussão sobre os pressupostos da neuropsicologia dita moderna, discorre-se sobre algumas etapas da evolução ${ }^{2}$ do pensamento que permitiram o surgimento e o estabelecimento da neuropsicologia enquanto ciência.

\section{Períodos históricos}

\section{Pré-história}

O sistema nervoso tal como o conhecemos hoje surgiu há cerca de 30.00035.000 anos; os seres que como nós o apresentam são ditos Homo sapiens sapiens ou simplesmente homens modernos. Nossos ancestrais mais próximos, chamados Homo sapiens neanderthalensis (homens antigos ou arcaicos), que viveram entre 130.000-35.000 anos, tinham um sistema nervoso diferente e conseqüentemente, uma mente diferente. Em outras palavras, assim como se admite, em relação ao gênero $\mathrm{Homo},{ }^{3}$ mudanças significativas no sistema nervoso (a mais óbvia relacionada ao aumento do tamanho do

1 Diferenciam-se os distúrbios de aprendizagem das dificuldades (problemas, disabilidades) de aprendizagem porque neles se admite haver sempre uma perturbação na neurologia da aprendizagem, identificada ou não pelas técnicas atuais de neuro-imagem. As expressões déficits, transtornos, lesões, entre outras, são igualmente utilizadas. Em outras palavras, pessoas com distúrbios de aprendizagem têm desordens comportamentais resultantes de disfunções neuronais. A inteligência do indivíduo pode ser normal, acima ou abaixo da média.

2 Evolução a partir de uma base biológica, o sistema nervoso. Concepção materialista.

3 Indícios moleculares consensuais sugerem que a família humana originou-se há cerca de 7 milhões de anos, quando espécies semelhantes aos macacos com um modo de locomoção bípede, ou ereta, evoluíram. Entre 3 e 2 milhões de anos atrás, houve uma espécie que desenvolveu um cérebro significantemente maior, dando origem ao gênero Homo. (LEAKEY, 1995, p. 14). 
cérebro), também se admite uma evolução da mente e, especificamente, da consciência humana.

Para Richard E. F. Leakey, um dos maiores paleontologistas do século $\mathrm{XX}$, uma atividade humana plena de consciência e que às vezes deixa a sua marca no registro arqueológico é o sepultamento deliberado dos mortos; isto porque nesta atividade podemos identificar claramente uma percepção da morte e, portanto, uma percepção do eu.

Na história humana, o primeiro indício de sepultamento deliberado, segundo Leakey (1995, p. 148), "é o sepultamento neanderthal há não muito mais que 100 mil anos (...). Antes de 100 mil anos atrás, não há indício de qualquer tipo de ritual que pudesse indicar consciência reflexiva". A ausência de tais indícios, contudo, como bem destaca este autor, não corrobora a hipótese da ausência de consciência, mas também não permite que seja acrescentada como apoio à existência da consciência. Leakey ainda deixa claro que esta não é, provavelmente, "a primeira mente humana" - o Homo erectus provavelmente tinha uma consciência reflexiva altamente desenvolvida (sua complexidade social, grande tamanho cerebral e uma provável habilidade lingüística, apontam para isso).

Assim, ao se perguntar quando, na pré-história humana a mente atingiu o estágio que ora experimentamos, a resposta, para Leakey, é em alguma época nos últimos 2,5 milhões de anos (período relacionado com a própria evolução do gênero Homo e com a origem de um cérebro maior).

Voltando a atenção para os "humanos como nós" (sapiens moderno), a literatura refere a descoberta de crânios trepanados ${ }^{4}$ datados entre $7.000 \mathrm{e}$ 20.000 anos, encontrados em vários continentes. Na falta de evidências documentais, pode-se apenas supor os motivos (terapêuticos? ritualistas?) para estas operações: tais especulações admitem que a tentativa consciente do homem de combater a doença é tão antiga quanto a própria consciência e que a medicina se originou de práticas mágicas e sacerdotais.

\section{Antigüidade}

Entre as mais antigas informações escritas sobre o sistema nervoso, destaca-se o papiro descoberto no Egito por Edwin Smith, no século XIX. O documento foi escrito em cerca de 1700 a.C., possivelmente pelo médico

4 Os sinais deixados pelos instrumentos confirmam o caráter operatório de grande número de trepanações, feitas em vida ou após a morte, assim como os sinais de regeneração nas brechas ósseas indicam a sobrevivência de vários operados. (MARGOTTA, 1998, p. 9). 
egípcio Inhotep, mas admite-se que ele se baseie em textos mais antigos, provavelmente do Antigo Império (cerca de 3000 a.C.). Esse papiro é um verdadeiro tratado de cirurgia e contém a descrição clínica detalhada de pelo menos 48 casos com os respectivos tratamentos racionais e prognósticos (favorável, incerto e desfavorável). Vários desses casos são importantes para a neurociência, pois neles se discute o encéfalo (o termo aparece pela primeira vez neste documento), as meninges, o líquor, e a medula espinhal. (BERNARDES DE OliveIRA, 1981, p. 30). O papiro Edwin Smith, contudo, constitui exceção. No cômputo geral, ainda por mais de dois mil anos, as concepções médicofilosóficas giraram em torno do empirismo e do sobrenatural.

$\mathrm{Na}$ antiga Grécia, a medicina era inicialmente dominada pelos filósofos cientistas e as discussões giravam em torno do problema corpo-alma. A partir do século $\mathrm{V}$ a.C. estabelece-se a diferenciação entre medicina e filosofia, e a "etiologia" da doença deixa de ser mitológica e passa a ser percebida em termos científicos. Para todos esses pensadores gregos, contudo, a saúde exigia a harmonia do corpo e da alma.

Entre as idéias defendidas, destacamos: a de Pitágoras (580-510 a.C.), que admitia que no encéfalo estava situada a mente, enquanto no coração localizavam-se a alma e as sensações; a de Alcmeon (cerca de 500 a.C.), que descreveu os nervos ópticos e investigou os distúrbios funcionais do encéfalo, considerando-o a sede do intelecto e dos sentidos; a de Hipócrates (cerca de 460-370 a.C.), que discutiu a epilepsia como um distúrbio do encéfalo, e o considerava como sede da inteligência e das sensações (tese cefalocentrista); a de Platão (427-347 a.C.), que considerava o encéfalo como sede do processo mental e julgava a alma tríplice, sendo o coração a sede da alma afetiva, o cérebro da alma intelectual, e o ventre da concupiscência (apetite sexual); a de Aristóteles (384-322 a.C.), que admitia ser o coração o centro das sensações, das paixões e da inteligência (tese cardiocentrista), enquanto o encéfalo tinha como função refrigerar o corpo e a alma; ${ }^{5}$ e a de Herófilo (335-280 a.C.), médico de Alexandria, que efetuou grandes avanços anatômicos, estudando com minúcias, entre outros, o sistema nervoso central e o periférico.

5 Aristóteles distinguia 3 tipos de alma: a vegetativa, comum a todos os seres animados, princípio da nutrição e da reprodução; a sensitiva, só existente nos animais, incluindo o homem, que lhes confere a sensibilidade que sentem e a racional ou intelectual, inicialmente considerada exclusiva dos homens (mais tarde esta idéia foi modificada). Ainda, para Aristóteles a alma não existia separada da matéria (corpo), à qual dá existência particular; por isso ela não podia ser imortal. (ABRÃO; COSCODAI, 2002, p. 61) . 


\section{Idade Média e Renascimento}

Já durante o período pré-medieval, a medicina de Cláudio Galeno, (cerca de 130-203), teve enorme projeção, mantendo-se incontestada durante mais de mil anos, tendo influenciado toda a Idade Média e até mesmo após o advento renascentista. ${ }^{6}$ Embora médico de gladiadores, o que lhe permitia investigar as conseqüências de lesões na medula e no cérebro, a maior parte de suas idéias sobre o funcionamento cerebral humano derivava de suas cuidadosas dissecações em animais.

Para Galeno, o encéfalo era formado de duas partes: uma anterior, o cerebrum e uma posterior, o cerebellum. Galeno deduziu (corretamente) que o cerebrum estava relacionado com as sensações, sendo também um repositório da memória, enquanto o cerebellum estava relacionado com o controle dos músculos. Os nervos eram condutos que levavam os líquidos vitais ou humores, permitindo que as sensações fossem registradas e os movimentos iniciados.

A doutrina humoral atingiu o seu apogeu na teoria de Galeno, mas admite-se que tenha sido elaborada pela escola hipocrática a partir da idéia présocrática de que o mundo era constituído de 4 elementos inalteráveis, que formavam a raiz de tudo: terra, ar, fogo, e água. Esses 4 elementos, por sua vez, eram dotados de 4 qualidades, opostas aos pares: quente e frio, seco e úmido (a terra era fria e seca, o ar quente e úmido, o fogo quente e seco, e a água fria e úmida). A transposição deste conceito para o comportamento/ temperamento humano deu origem à concepção dos 4 líquidos essenciais (sangue, fleuma, bile amarela - pituíta, e bile negra - atrabílis) que, quando em equilíbrio e harmonia (eucrasia) asseguravam a saúde do indivíduo, enquanto a doença era devida ao seu desequilíbrio e desarmonia (discrasia). Assim, segundo a predominância de um ou outro desses 4 humores, tinha-se o indivíduo otimista, falante, irresponsável (tipo sanguíneo); calmo, sereno, lento, impassível (tipo fleumático); explosivo, ambicioso (tipo colérico); introspectivo, pessimista (tipo melancólico). As expressões "bom humor", "mau humor", "bem humorado", "mal humorado", são reminiscências dos conceitos de eucrasia e discrasia. Para Oliveira (1981, p. 113), este é o princípio da psiquiatria e da teoria química aplicada às atividades cerebrais.

6 O princípio fundamental da vida, segundo Galeno, era o pneuma, que se manifestava de 3 formas e com 3 tipos de função: espírito animal (pneuma psychicon), localizado no cérebro, centro das percepções nervosas e do movimento; espírito vital (pneuma zoticon), centrado no coração e que regula o fluxo de sangue e a temperatura do corpo; espírito natural (pneuma physicon), residente no fígado, centro da nutrição e do metabolismo. (MARGOTTA, 1998, p. 41). 
A partir da morte de Galeno, o conhecimento médico sofreu um processo de decadência qualitativa e quantitativa. Nesta decadência, dois fatores merecem ser destacados: primeiro, a ampla aceitação da doutrina cristã de que o corpo tinha pouca ou nenhuma importância em comparação com a alma (daí os estudos que tinham por objeto o corpo serem considerados desprezíveis e indignos); segundo, a crença (a princípio rejeitada pela Igreja, mas depois absorvida por aqueles que professavam a religião), de que "a forma humana simboliza a estrutura do Mundo Maior, que o microcosmo é construído nos moldes do macrocosmo, que o homem é um epítome do Universo". (SINGER, 1996, p. 84). Daí porque o esquema do homem zodiacal, no qual os signos do zodíaco eram escritos primeiramente ao redor e depois sobre as várias partes do corpo que se supunha governassem, estava entre os produtos mais comuns da época.

Dada a manutenção da estreita relação da medicina com as correntes filosófico-religiosas predominantes, a leitura de Aristóteles que, de início, era condenável pela Igreja, acabou por elevá-lo à culminância de fonte de conhecimentos comparável à Bíblia; e os escritos de Galeno que, sob muitos ângulos encerravam fundo religioso acentuado, foram aceitos e mantidos como dogmas. Em outras palavras, o pensamento médico ocidental durante a Idade Média, tentou ajustar as doutrinas biológicas e médicas de Aristóteles e Galeno aos ideais da Igreja. Daí, por exemplo, as câmaras ventriculares do cérebro, descritas por Galeno, terem sido ajustadas à idéia do corpo como abrigo natural da alma, dando suporte à chamada hipótese de localização ventricular (doutrina ventricular). O número de ventrículos, igual a três, representando a Santíssima Trindade, ajustava-se ao sentimento religioso reinante, ou seja, destacava o esforço de munir a fé de argumentos racionais, de promover a conciliação entre a fé e a razão, aceitando a noção das funções cerebrais localizadas nos ventrículos (achando-se na célula anterior as sensações, na média o pensamento, e na posterior a memória).

A partir do final do período medieval, teve início um movimento cultural caracterizado pelo estudo de obras gregas e romanas até então desconhecidas. Esse movimento cultural coincide com o Humanismo, parte do que hoje chamamos de Renascença ou Renascimento. ${ }^{7}$

${ }^{7}$ Note-se que a idéia do corpo como máquina, do mundo material como máquina, é dos pensadores renascentistas - para eles, a ordenação do mundo natural era a manifestação da inteligência de algo para além da natureza (o criador divino e senhor da natureza), e não, como admitiam os gregos, a inteligência da própria natureza. 
Iniciado na Itália, a intensa renovação artística e cultural produzida neste período garantiu, entre outros, um grande avanço no estudo da anatomia humana graças principalmente, às obras de Leonardo da Vinci (1452-1519) e Andreas Vesalius (1514-1564), que contribuíram de forma decisiva.

A observação e a extraordinária habilidade técnica de Da Vinci, representada por meio de seus desenhos anatômicos, destacam este autor como criador da ilustração médica. Em relação ao sistema nervoso, sua mais notável contribuição foi a realização de moldes dos ventrículos cerebrais (a partir da injeção de cera líquida aquecida, que se solidificava após refrigeração). Tornou-se evidente, então, que não eram três, mas quatro os ventrículos cerebrais (dois laterais, um em cada hemisfério cerebral, o terceiro, localizado na altura do tronco encefálico, e o quarto ventrículo, localizado na altura do cerebelo). Os maravilhosos desenhos de Da Vinci, no entanto, permaneceram ignorados durante cerca de 300 anos e o homem celebrado como pai da anatomia foi Vesalius que, em 1543, publicou sua obra monumental De humani corporis fabrica libri septem, dividida em sete volumes, freqüentemente referida como Fabrica, considerada uma das obras mais importantes já publicadas. Além de representar um marco na história da medicina, este livro tem alta significação como obra de arte - não apenas pelos estudos terem sido feitos em cadáveres humanos (rompendo a tradição imposta por Galeno de estudar a anatomia nos animais para transplantá-la para o homem), o que assegurava a qualidade da expressão corporal de suas figuras, mas pelo fato de ser um dos primeiros exemplos de ilustrações impressos com fundo panorâmico tirado do natural. (BERNARDES DE OLIVEIRA, 1981, p. 189).

\section{Séculos XVII e XVIII}

Durante a segunda metade do século XVII e o início do século XVIII, o problema corpo $x$ alma motivou vários pesquisadores na proposição de novas interpretações; tais idéias, contudo, tinham como característica principal o fato de que se baseavam em especulações e não em observações clínicas ou experimentais. Uma das teorias melhor conhecida é a de René Descartes (15961650); esta teoria admitia que a alma (denominada res cogitans, "a coisa pensante") era uma entidade livre, não substantiva, imaterial, indivisível e o corpo (res extensa, "extensão da coisa") uma parte mecânica, material, divisível. Embora diferentes, a alma interagia com o corpo por meio da glândula pineal, que também funcionava como centro de controle. Assim, no conceito cartesiano, a alma (o espírito) transcende o corpo e este é matéria dotada de movimento, como uma máquina. 
Esta teoria provocou uma dissociação mente e corpo e os indivíduos passaram a se identificar com a sua mente racional e não com o organismo (SANVITO, 1991, p. 152); surgiram então as expressões "corpo sem alma", "alma sem corpo", e "de corpo e alma" (completamente, inteiramente).

Damasio (1996, p. 279) discute a afirmação "penso, logo existo" (em francês, "je pense, donc je suis"), publicada por Descartes, em 1637, na obra $O$ discurso do método ${ }^{8}$ e depois, em 1644, na obra Princípios de Filosofia (em latim, cogito ergo sun). Para Damasio, a referida citação afirma o oposto daquilo que ele acredita ser verdade acerca das origens da mente e da relação entre a mente e o corpo. Isso porque o conhecimento atual sobre o desenvolvimento filogenético (entre espécies biológicas), e ontogenético (em uma espécie biológica; no caso, Homo sapiens) permite-nos compreender que muito antes do aparecimento da humanidade, os seres já eram seres. O surgimento de uma consciência elementar e com ela uma mente simples, que com uma maior complexidade possibilitou o pensar e, mais tarde o uso de linguagens para comunicar e melhor organizar os pensamentos, é anterior ao surgimento dos humanos modernos. Mesmo no presente, quando viemos ao mundo e nos desenvolvemos, começamos por existir, e só mais tarde pensamos; daí, para Damasio (1996, p. 279) “existimos e depois pensamos e só pensamos na medida em que existimos, visto o pensamento ser, na verdade, causado por estruturas e operações do ser".

A crença de Descartes em uma mente separada do corpo, uma mente desencarnada, contribuiu para alterar o rumo da medicina, ajudando-a a abandonar a abordagem da mente-no-corpo que predominou de Hipócrates até o Renascimento, e moldou a forma peculiar como a medicina ocidental aborda a investigação e o tratamento da doença (prática médica). Como resultado, as conseqüências psicológicas das doenças do corpo, propriamente dito, as chamadas doenças físicas, são normalmente ignoradas ou levadas em conta muito mais tarde; mais negligenciados ainda são os efeitos dos conflitos psicológicos no corpo (DAMASIO, 1996, p. 282). Ainda, a idéia cartesiana da mente separada do corpo explica porque ainda hoje muitos investigadores em psicologia se julgam capazes de entender a mente sem nenhum recurso à neurobiologia ("psicologia sem cérebro") 9 ou porque para muitos

8 DESCARTES, René. Discurso do método. Lisboa: Edições 70, 1986.

9 A expressão Psicologia sem cérebro nos remete a correntes psicológicas que não têm qualquer preocupação com os substratos anatômicos cerebrais e com os mecanismos neurofisiológicos do comportamento e dos processos cognitivos. Entre estas correntes, podemos citar o Behaviorismo e a Epistemologia Genética. 
neurocientistas a mente pode ser perfeitamente explicada em termos de fenômenos cerebrais, deixando de lado o resto do organismo e o meio ambiente físico e social (ignorando também que o próprio meio é um produto das ações anteriores do organismo).

\section{Século XIX}

O século XIX foi, entre outros, marcado pelo nascimento da biologia e pela revolução de idéias decorrentes da teoria da seleção natural proposta pelo naturalista Charles Robert Darwin (1809-1882). A concepção de mente, enquanto atributo supremo e divino do ser humano, fortemente marcada pelo dogma e poder religioso, deixava os vapores etéreos para se encarnar no sistema nervoso humano. A descoberta de que o córtex cerebral, até então considerado homogêneo do ponto de vista funcional, apresentava áreas anatomicamente definidas, deu suporte à idéia de que diferentes funções mentais estavam alojadas nas diferentes porções do córtex. O mais ilustre e provavelmente o primeiro proponente da localização cerebral das funções mentais foi o austríaco Franz Joseph Gall (1758-1828). Gall acreditava que o cérebro era na verdade um conjunto de órgãos separados, cada um dos quais controlava uma "faculdade" (aptidão) inata separada (WALSH, 1994, p. 14). Originalmente, Gall postulou a existência de 27 "faculdades afetivas e intelectuais" (entre elas, benevolência, agressividade, sentido da linguagem, amor parental); este número foi posteriormente aumentado. O desenvolvimento de uma determinada "faculdade" causava uma hipertrofia na zona cortical correspondente; esta zona hipertrofiada exercia pressão sobre a calota craniana, produzindo neste local uma pequena saliência óssea. As funções pouco desenvolvidas ou ausentes produziam, ao contrário, uma depressão na superfície craniana. Assim, pelo processo da cranioscopia (apalpação das proeminências) o praticante da Frenologia ${ }^{10}$ poderia determinar a natureza das propensões do indivíduo. ${ }^{11}$ E como as "faculdades" se encontravam em áreas circunscritas, essas idéias deram origem à chamada corrente localizacionista (e ao conseqüente surgimento dos mapas frenológicos).

${ }^{10} \mathrm{O}$ termo frenologia (do grego phrén, phrenós = alma, inteligência, espírito), foi cunhado por Johann C. Spurzheim (1776-1832); enquanto colaborador de Gall, ele o ajudou a disseminar suas idéias nos Estados Unidos e na Europa.

${ }^{11}$ Note-se que a crença de que o formato da cabeça é determinante na forma de pensar é muito anterior à Idade Média, quando se tinha por hábito moldar o crescimento da cabeça das crianças que estavam destinadas a ocupar posições importantes e diferenciadas na sociedade, como sacerdotes e chefes. 
Descartada a partir de meados do século XX enquanto procedimento científico, a Frenologia, ainda hoje apresenta muitos adeptos. Quem nunca ouviu as expressões "cabeça chata" e "testa baixa"; elas se mantêm de uso corrente e são usadas no cotidiano para denotar pouca inteligência ou mesmo características de sujeitos de "raça inferior" (numa clara alusão preconceituosa).

Gall estabelecia a função a partir do sintoma, isto é, se a lesão de uma determinada zona do cérebro causava perturbação de um determinado comportamento, isto se devia ao fato desta atitude ter sua sede nesta região.

Admitir que cada parte do córtex cerebral tem uma função diferente deveria permitir, por exemplo, que se provocasse deficiências comportamentais específicas por meio da remoção de porções circunscritas desse córtex; com o intuito de testar essa hipótese, muitos cientistas começaram a provocar lesões cerebrais em animais de laboratório e a observar suas conseqüências. Para Herculano-Houzel (2001, p. 21), estes experimentos marcaram o nascimento da neurociência experimental que conhecemos hoje.

Entre os opositores do localizacionismo, merece destaque o fisiologista francês Marie-Jean-Pierre Flourens (1794-1867); este acreditava que as funções mentais não dependiam de áreas particulares do sistema nervoso, mas que este funcionava como um todo, de modo orquestrado, integrado. Suas idéias anteciparam a noção de equipotencialidade (plasticidade neuronal), isto é, a capacidade de outras partes do cérebro assumirem funções do tecido neural lesado e deram início ao movimento que resultou na corrente holista (nãolocalizacionista, unitarista) da função cerebral.

O século XIX foi também particularmente importante por ter demarcado o nascimento da neuropsicologia da linguagem. Isto porque, embora a literatura inclua registros de observações clínicas sobre distúrbios de linguagem em decorrência de traumatismo cerebral feitos há milhares de anos, ${ }^{12}$ foi apenas no século XIX que as correlações anatomo-clínicas entre lesões cerebrais e patologia da linguagem tornaram-se um importante foco de atenção.

Entre os estudiosos que investigaram indivíduos com comprometimento na linguagem decorrentes de lesão cerebral, destaca-se o médico e antropólogo francês Pierre-Paul Broca (1824-1880) e o neurologista alemão Carl Wernicke (1848-1905).

${ }^{12}$ No papiro cirúrgico Edwin Smith encontra-se, por exemplo, o registro de um homem que devido a uma lesão cerebral perdeu a capacidade de falar, sem paralisia de sua língua. Já entre os escritos hipocráticos, há referência a uma paciente que perdeu a capacidade de falar porque o lado direito de seu cérebro estava paralisado devido a convulsões. 
Em 1865, baseando-se em vários estudos anatomo-patológicos de pacientes com perda da fala ("amnésia verbal"), Broca estabeleceu para sede da linguagem articulada a parte posterior da terceira circunvolução frontal do hemisfério esquerdo (região atualmente conhecida como área de Broca). $\mathrm{O}$ distúrbio descoberto por Broca foi por ele denominado de afemia, mas na literatura médica o termo consagrado foi "afasia". ${ }^{13}$ Anos depois, Broca publicou a famosa frase "nous parlons avec l'hémisphère gauche" (WALSH, 1994, p. 17), que se tornaria um marco na história do funcionamento cerebral. A localização da sede da faculdade de expressão oral no hemisfério esquerdo não implicava apenas na aceitação de uma assimetria funcional dos hemisférios cerebrais; Broca também acreditava que, no que tange a linguagem expressiva, o hemisfério esquerdo era dominante sobre o direito, ou seja, o direito exercia apenas papel coadjuvante ou secundário.

Note-se que a idéia da dominância hemisférica é precursora da concepção moderna de especialização funcional dos hemisférios cerebrais que, em síntese, admite que os dois hemisférios sempre trabalham em conjunto, mas como detêm especializações funcionais, um se encarrega de um grupo de funções enquanto o segundo encarrega-se de outro; no caso dos dois hemisférios realizarem a mesma função, as diferenças residem nos modos de execução ou estratégias funcionais de cada hemisfério. Voltaremos a este assunto posteriormente.

Em 1874, Wernicke mostrou que, assim como uma lesão unilateral anterior é suficiente para perturbar a expressão oral, uma lesão do mesmo lado localizada posteriormente no hemisfério esquerdo causa freqüentes problemas de compreensão da linguagem falada. Esses problemas são associados a uma linguagem fluente, mas aberrante, sendo que a pessoa erra ao usar palavras ou sons.

A área atingida pelas lesões estudadas por Wernicke recebeu posteriormente, em sua homenagem, a denominação de área de Wernicke e atualmente tem sido considerada restrita ao terço posterior do giro temporal superior esquerdo, incluindo a parte oculta do assoalho do sulco lateral de Sylvius. (LENT, 2001, p. 636).

Deve-se também a Wernicke, a elaboração do primeiro modelo científico do processamento lingüístico - este modelo considera que a área de Broca

13 O termo "afasia" foi cunhado, segundo alguns autores, por Armand Trousseau (18011867) e, segundo outros, por Sigmund Freud (1856-1939). Atualmente, entende-se por afasia o distúrbio de linguagem devido a lesões nas regiões envolvidas com o processamento lingüístico. Exclui-se, portanto, as alterações de linguagem decorrentes de lesões nos sistemas motor, atencional, etc. (LENT, 2001, p. 635) . 
contém os programas motores da fala (isto é, as memórias dos movimentos, que permitem a estes expressar os fonemas, compô-los em palavras e estas em frases), enquanto a área descrita por Wernicke contém as memórias dos sons que compõem as palavras, possibilitando sua compreensão. Quando as duas áreas se conectam, a pessoa associa a compreensão das palavras ouvidas com a sua própria fala. Anatomicamente, as duas áreas são conectadas por um feixe de fibras nervosas que se encontra imerso na substância branca cortical e se denomina feixe arqueado. Assim, Wernicke previu corretamente que uma lesão desse feixe deveria provocar uma "afasia de condução", na qual os pacientes seriam capazes de apresentar uma fala fluente, mas cometendo erros de repetição e de resposta a comandos verbais.

A descoberta do fato de que formas complexas de atividade mental podiam ser localizadas em regiões circunscritas do córtex cerebral da mesma forma que funções elementares (tais como movimento e sensação), suscitou a realização, por mais de meio século, de um grande número de estudos que visavam demonstrar que todos os processos mentais complexos eram o resultado do funcionamento de áreas locais individuais. Tal abordagem de estudo é dita reducionista.

Entre os grandes opositores dos localizacionistas estreitos, destaca-se o neurologista inglês John Huhlings Jackson (1834-1911). Baseado em detalhadas observações clínicas, Jackson propôs que a organização cerebral dos processos mentais complexos devia ser abordada do ponto de vista do nível da construção de tais processos, ao invés do da sua localização em áreas particulares do cérebro. Assim, Jackson formulou uma "teoria de organização neurológica da função mental" que, em síntese, admite que essa não é resultante do funcionamento de um grupo circunscrito de células que se organizam em "centros", mas resulta de uma complexa organização "vertical" ditada pela evolução cerebral. Esta função é representada primeiro num nível "inferior" (automático; medula e tronco encefálico), posteriormente re-representada em um nível "intermediário" (voluntário; porções motora e sensorial do córtex cerebral), e finalmente re-re-representada em um nível "superior" (voluntário; porções frontais do córtex cerebral). Daí, segundo Jackson, a localização de um sintoma que acompanha uma lesão de uma determinada área não pode ser identificada com a localização dessa lesão (ou seja, existe uma grande diferença entre localizar a área lesada que destruiu a linguagem e localizar a linguagem em alguma área do cérebro). A função pode se originar de uma maneira muito mais complexa e pode ter uma organização cerebral bastante diferente, de acordo com a "noção de dissolução de função" (passagem do mais organizado para o menos organizado, do mais complexo para o mais 
simples, do voluntário para o automático). Esta hipótese de Jackson foi adotada e desenvolvida cerca de 50 anos mais tarde, reaparecendo nos escritos de eminentes neurologistas do século XX.

Cabe ainda destacar que o tecido neural só se tornou tema da ciência neurologia no fim do século XIX, quando os estudos do médico italiano Camillo Golgi ${ }^{14}$ (1843/4-1926) e do histologista espanhol Santiago Ramón y Cajal $^{15}$ (1852-1934) descreveram em detalhes a estrutura das células nervosas. Ainda, em 1897, Sir Charles Scott Sherrington (1857-1952) propôs os termos "sinapse", definido como o local de contato entre dois neurônios, e "transmissão sináptica", definida como a passagem de informações por meio da sinapse. Estes conceitos, contudo, permaneceram como concepções teóricas por muito tempo, pois só a partir da década de 50 do século $\mathrm{XX}$, com o uso do microscópio eletrônico e das técnicas de registro dos sinais elétricos produzidos pelos neurônios, foi possível determinar experimentalmente suas bases morfológicas e funcionais. (LENT, 2001, p. 99).

\section{Séculos $X X-X X I$}

Segundo Engelhardt, Rozenthal e Laks (1995, p. 112), a neuropsicologia moderna começa com Donald Olding Hebb (1904-1985), Karl Spencer Lashley (1890-1958) e Aleksandr Romanovitch Luria (1902-1977). O termo neuropsicologia foi utilizado pela primeira vez em 1913, mas o seu desenvolvimento começou nos anos 40, a partir dos trabalhos de Hebb. Em 1949, ${ }^{16}$ este autor propôs uma teoria de funcionamento do córtex cerebral a partir de conexões neuronais modificáveis, isto é, cujas possibilidades de conexão de umas com as outras são múltiplas. Em outras palavras, Hebb propôs uma "teoria para a memória com base na plasticidade sináptica"; esta teoria, em síntese, admite que a transmissão de mensagens entre os neurônios pode ser

${ }^{14}$ Em 1875, Golgi desenvolveu um método de coloração por prata que, ao microscópio, revelava toda a estrutura do neurônio, incluindo o corpo celular (soma) e seus prolongamentos - os dendritos e os axônios.

${ }^{15}$ Ramón y Cajal usou o método de coloração por prata de Golgi para marcar células individuais, mostrando que o tecido neural não era uma massa contínua e sim uma rede de células distintas. Ele também propôs a "doutrina do neurônio" - princípio que admite que os neurônios individuais são os sinalizadores primários do sistema nervoso, e "o princípio da polarização dinâmica", segundo o qual a informação desloca-se em apenas uma direção dentro do neurônio (usualmente dos dendritos para o axônio, chegando às terminações nervosas).

${ }^{16}$ HEBB, D. O. The organization of behavior: a neuropsychological theory. New York: John Wiley, 1949. 
regulada, não sendo um fenômeno rígido e imutável, mas algo modulável de acordo com as circunstâncias. Desse modo, o armazenamento de memória não repousaria na modificação das propriedades dos neurônios e tampouco implicaria na presença de circuitos determinados e únicos, mas "o traço mnésico estaria ligado à formação e à persistência de uma rede de conexões entre as células, embora nenhuma delas contenha a informação necessária à restituição da lembrança". (SANvito, 1991, p. 89). Atualmente, a teoria de Hebb tornou-se um modelo celular e molecular da memória.

Os trabalhos experimentais de Lashley, por outro lado, sugeriram fortemente que as funções cerebrais requerem a participação de grandes massas cerebrais de tecido nervoso e por isso ele formulou uma teoria de funcionamento cerebral denominada de "ação de massa", que diminui a importância dos neurônios individuais, das conexões neuronais específicas, e das regiões cerebrais distintas, funcionalmente especializadas. Segundo esta teoria, portanto, é a massa cerebral, e não seus componentes neuronais, que é importante para o funcionamento cerebral. As conclusões de Lashley, a favor do papel de "ação de massa" e da equipotencialidade da função cerebral, dado ao rigor e precisão dos estudos (incluindo experimentação associada à observação, quantificação dos dados, controle anatômico estrito dos preparados, uso de grupos, controle e verificação estatística dos dados), influenciaram profundamente o conhecimento neuropsicológico.

Já Luria, influenciado, entre outros, por Ivan Petrovitch Pavlov (1849 1936), Pioter Kuzmitch Anokhin (1898-1974), e Lev Semiónovitch Vigotski (1896-1934), investigou as funções superiores nas suas relações com os mecanismos cerebrais e desenvolveu a noção do sistema nervoso funcionando como um todo, considerando o ambiente social como determinante fundamental dos sistemas funcionais responsáveis pelo comportamento humano. Luria afirmava que as funções psíquicas do homem são produtos de uma larga evolução, possuem uma estrutura complexa e estão sujeitas a modificações em seus elementos constitutivos. Desse modo, não podem ser localizadas senão dinamicamente, em constelações de trabalho, com a ajuda de diferentes neurônios. Segundo Luria "toda atividade mental humana é um sistema funcional complexo efetuado por meio de uma combinação de estruturas cerebrais funcionando em concerto, cada uma das quais dá a sua contribuição particular para o sistema funcional como um todo". (LURIA, 1981, p. 23). ${ }^{17}$

17 As idéias de Luria sobre o "cérebro em funcionamento" são seguramente um desenvolvimento do conceito original dos sistemas funcionais de Anokhin, ou da Teoria dos Sistemas Funcionais do Organismo, criada por este autor. (BURZA, 1986, p. 27) . 
Enquanto sistema dinâmico, o cérebro luriano é constituído de três unidades funcionais básicas cuja participação é necessária para qualquer tipo de atividade mental; cada uma delas exibe uma estrutura hierarquizada própria, formada por pelo menos três zonas corticais construídas umas sobre as outras. As propriedades funcionais de cada uma dessas três unidades ou blocos funcionais podem ser assim resumidas (LURIA, 1981, p. 27): a primeira unidade regula o estado do córtex cerebral, alterando seu tono e mantendo o estado de vigília (sua estrutura mais importante é a formação reticular, uma rede nervosa "não-específica" que desempenha gradualmente a sua função de modificar o estado de atividade cerebral); a segunda unidade tem como função primária receber, analisar e armazenar informações, e inclui as regiões visuais (occipital), auditivas (temporal), e sensorial geral (parietal) do córtex cerebral; finalmente, a terceira e última unidade funcional elabora os programas de comportamento, responde pela sua realização e participa do controle de sua execução (suas estruturas se localizam nas regiões anteriores, frontais ou pré-frontais, dos hemisférios cerebrais). A obra de Luria tem subsidiado atualmente boa parte dos estudos neuropsicológicos realizados por educadores, com vistas a investigar a aprendizagem em crianças e adolescentes. (ANTUNHA, 2000, p. 33; ANTUNHA, 2002, p. 116; CIASCA, 2000, p. 127).

A partir da década de 60 , um grande número de pesquisadores desenvolveu estudos sobre especialização dos hemisférios cerebrais. Entre estes estudos destaca-se os realizados por Roger W. Sperry (1913-1994), que lhe garantiu o prêmio Nobel de medicina e fisiologia em 1991. A partir de experimentos realizados com pessoas com o cérebro dividido (comissurotomizados) ${ }^{18}$ e com indivíduos normais, Sperry demonstrou que as especialidades dos hemisférios podem ser diferentes, e que raramente a especialização hemisférica significa exclusividade funcional.

Assim, por exemplo, o hemisfério esquerdo controla a fala em mais de $95 \%$ das pessoas, mas isso não significa que o direito não participe desta função - é a prosódia do hemisfério direito que confere à fala nuances afetivas essenciais para a comunicação. Outro exemplo, se a questão é o reconhecimento de faces, o hemisfério direito é especializado na identificação de seus aspectos gerais (homem ou mulher, criança ou adolescente), enquanto o es-

18 As "comissuras cerebrais" são três: o corpo caloso (a maior delas), a comissura anterior e a comissura do hipocampo. Enquanto feixes de fibras nervosas, as comissuras conectam ambos os hemisférios, transmitindo informações entre os hemisférios cerebrais. As comissuras são responsáveis por unificar os campos sensoriais (principalmente os hemicampos visuais) e sincronizar o processamento funcional de ambos os hemisférios (LENT, 2001, p. 645). 
querdo é melhor no reconhecimento do dono de cada face (Maria ou Marta?). Ao ser divulgada pela mídia, a idéia da especialização hemisférica foi transformada numa concepção simplista do funcionamento cerebral, onde um dos hemisférios seria, entre outros, o "verbal", o "racional", enquanto o outro seria o "não-verbal", o "intuitivo"; daí denominar-se o hemisfério esquerdo de "intelectual" e o direito de "artístico". Tais dicotomias exageradas resultaram em recomendações não-científicas do tipo "pense com o hemisfério direito", "aja com o hemisfério esquerdo", entre outras, e na crença equivocada de muitos educadores de que esta ou aquela atividade realizada pelo aluno propicia apenas o desenvolvimento de um dos hemisférios cerebrais. (SPRINGER; DEUTSCH, 1998, p. 328).

Recentemente, os sistemas lingüísticos foram tratados pelos psicolingüistas sob uma abordagem neuropsicológica, passando-se a produzir obras especializadas nas bases neurais da linguagem. ${ }^{19}$ Entre tantas contribuições, destacam-se as revisões conceituais sobre as áreas de Broca e de Wernicke, anteriormente citadas.

O "modelo neurolingüístico" proposto por Wernicke foi substituído pelo "modelo neuroanatômico conexionista da linguagem falada", que surgiu a partir da análise dos sintomas de pacientes com lesões pequenas e envolve a interação de diversas áreas corticais, mais restritas do que as definidas por Broca e Wernicke. Pelo modelo conexionista, a área de Wernicke não é a responsável pela compreensão do significado das palavras, mas faria a identificação das palavras como tal, isto é, seria uma das sedes do léxicon fonológico. A afasia de compreensão propriamente dita seria típica de lesões mais posteriores, que atingem o giro angular e o supramarginal; nestas regiões estaria uma das sedes do léxicon semântico ou mesmo o centro conceitualizador. Pacientes com lesões nestes locais repetem corretamente as palavras, mas não entendem o que repetiram. Outro tipo de afasia de compreensão surge a partir de lesões dos giros temporais médios e inferior (também locais do léxicon semântico); esta afasia é denominada anômica fluente porque os pacientes têm fluência verbal, mas incapacidade de identificar nomes de pessoas, animais ou objetos. A revisão feita sobre a área de Broca considera que os portadores de distúrbios de expressão mais severos apresentam alguma disartria (dificuldade de articular a fala; um distúrbio claramente motor), afasia anômica

${ }^{19}$ CAPLAN, D. ; CARR, T.; GOULD, J. et al. Language and comunication. In: ZIGMOND, M. J. et al. (Orgs). Fundamental neuroscience. New York: Academic Press, 1999. p. 1487-1519. 
não-fluente (fala dificultada principalmente nos verbos) e agramatismo (dificuldade de construir frases gramaticalmente corretas). Contudo, nos casos de lesões mais restritas, esses sintomas aparecem dissociados; por exemplo, anomia com disartria surge quando as lesões envolvem, além da área de Broca, as regiões motoras e pré-motoras posteriores da fala. (LENT, 2001, p. 638).

A partir da segunda metade do século XX, a neuropsicologia firmou-se efetivamente enquanto área de estudo, e embora a linguagem tenha sido a área mais amplamente investigada, diversos temas têm sido enfatizados nos últimos anos tais como: a atenção, a percepção visual e auditiva, e a memória.

Ainda entre os avanços obtidos, destacam-se a introdução e o desenvolvimento de técnicas de observação do cérebro e/ou de sua atividade (tomografia computadorizada, ressonância magnética, tomografia por emissão de pósitrons, entre outros), o aperfeiçoamento dos instrumentos de avaliação neuropsicológica, e o desenvolvimento de métodos de intervenção com o objetivo de obter a restauração de funções psíquicas superiores comprometidas por lesão cerebral.

As técnicas de imagem funcional computadorizada do sistema nervoso (que podem produzir imagens precisas do fluxo sangüíneo cerebral ou do metabolismo neuronal), permitem concluir fortemente em favor da localização cerebral das funções neurais (mesmo das mais complexas, como a linguagem). As diferentes regiões, contudo, não funcionam isoladamente, mas apresentam alto grau de interação, ou seja, não há uma função pura mas uma combinação bastante complexa de ações psicológicas e fisiológicas em cada comportamento que o indivíduo realiza.

\section{Considerações finais}

A questão "de que forma a mente se relaciona com o cérebro?" permanece ainda hoje como um problema sem solução. De uma forma resumida, podemos afirmar que duas grandes correntes filosóficas se destacaram quanto ao modo de interpretar esta questão: o dualismo e o monismo.

$\mathrm{O}$ dualismo admite a coexistência de dois princípios irredutíveis, em qualquer ordem de idéias; no caso, dualismo da alma e do corpo, da matéria e do espírito. Em outras palavras, para os dualistas, a mente (o espírito) e o cérebro (a matéria) são duas entidades distintas. Dentre seus adeptos, há os 
que acreditam que a mente e o cérebro são duas entidades independentes e não relacionadas (por exemplo, René Descartes), e os que preferem considerar que a mente e o cérebro se relacionam de algum modo, embora nunca tenham explicado convincentemente como. (KOLB; WHISHAW, 1990, p. 327). Por exemplo, John Carew Eccles (1903-1997) propunha que a mente seria inicialmente um produto do cérebro, mas capaz de adquirir independência dele - seria uma propriedade emergente do cérebro, obedecendo a uma lógica própria, independente. Já Roger W. Sperry admitia que a mente era uma entidade distinta do cérebro, produzida por ele e emergente, mas, além disso, capaz de influir sobre o cérebro, modificando-o.

O monismo, por outro lado, pode ser definido como uma doutrina filosófica segundo a qual o conjunto das coisas pode ser reduzido à unidade, quer do ponto de vista de sua substância, quer do ponto de vista das leis (lógicas ou físicas) pelas quais o universo se ordena. (FERREIRA, 1986, p. 1153). Para os monistas, portanto, a mente e o cérebro constituem uma unidade, em que um é mera propriedade do outro. Dentre os monistas, ${ }^{20}$ destacam-se os idealistas (espiritualistas), que acreditam que a matéria é mera criação da mente (espírito), e os materialistas, que acreditam na primazia da matéria e admitem que todas as funções psicológicas são originadas da atividade cerebral. Jean Piaget (1896-1980), por exemplo, era idealista; daí se entender porque a teoria do desenvolvimento da inteligência criada por ele não tinha qualquer preocupação com os substratos anatômicos cerebrais e com os mecanismos neurofisiológicos do comportamento e dos processos cognitivos. Vigotski e Luria, por outro lado, eram materialistas e ao criar e desenvolver a sua teoria, partiram das idéias evolutivas de Charles R. Darwin e estenderam os conceitos biológicos de desenvolvimento filogenético e ontogenético, para uma teoria sociohistórica (sociocultural) dos processos mentais superiores, destacando as relações entre o funcionamento intelectual e a cultura da qual os indivíduos fazem parte. (VYGOTSKY; LURIA, 1996, p. 27). Em outras palavras, Vigotski e Luria discutiram as relações entre desenvolvimento e aprendizagem a partir do pressuposto básico de que a mente organiza-se na sociedade. (VYGOTSKY; LURIA; LEONTIEV, 1988, p. 39). Atualmente, os conceitos vigotskianos de "aprendizagem colaborativa" e de "zona de desenvolvimento proximal" são bastante familiares para muitos profissionais da educação; por outro lado, o conhecimento dos estudos neuropsicológicos lurianos tem despertado interesse cres-

${ }^{20}$ Ao idealismo se vinculam filósofos muito diferentes, tais como Platão (427-347 a.C), Immanuel Kant (1724-1808) e George W.F. Hegel (1770-1831). 
cente dos educadores interessados em compreender a causa do não-aprendizado do aluno.

Ao longo do tempo, os estudiosos discutiram os níveis de existência do sistema nervoso, creditando, quase sempre, mais importância a um deles. Assim, a linguagem, a memória e a percepção (nível psicológico) seriam reduzidas a suas manifestações fisiológicas; a motricidade e as sensações (nível fisiológico) seriam reduzidas a suas manifestações celulares; e os fenômenos celulares a suas manifestações moleculares (nível bioquímico ou microfisiológico). Atualmente, contudo, estas visões reducionistas não são aceitas como explicação, embora possam resultar em bons métodos de estudo. Assim, concorda-se com Lent $(2001$, p. 3) quando este afirma que os níveis de existência do sistema nervoso não são uns conseqüências dos outros, mas coexistem simultaneamente, em paralelo.

\section{REFERÊNCIAS}

ABRÃO, B. S.; COSCODAI, M. (Orgs). História da filosofia. São Paulo: Bett Seller, 2002.

ANTUNHA, E. L. G. Jogos sazonais - coadjuvantes do amadurecimento das funções cerebrais. In: OLIVEIRA, Vera B. de. (Org.). O brincar e a criança do nascimento aos seis anos. Petrópolis: Vozes, 2000.

ANTUNHA, E. L. G. Avaliação neuropsicológica dos sete aos onze anos. In: BOSSA, N. A.; OLIVEIRA, V. B. de. (Orgs.). Avaliação psicopedagógica da criança de sete a onze anos. 10. ed. Petrópolis: Vozes, 2002.

BERNANRDES DE OLIVEIRA, Antônio. A evolução da medicina: até o início do século XX. São Paulo: Pioneira/Secretaria de Estado da Cultura, 1981.

BURZA, J. B. Cérebro, neurônio, sinapse: teoria do sistema funcional de P. K. Anokhin. São Paulo: Ícone, 1986.

CAPLAN, D. et al. Language and comunication. In: ZIGMOND, M. J. et al. (Orgs.). Fundamental neuroscience. Nova York: Academic Press, 1979.

CIASCA, S. M. Avaliação neuropsicológica e neuroimagem nos distúrbios de aprendizagem: leitura e escrita. In: ASSOCIAÇÃO BRASILEIRA DE DISLEXIA. Dislexia: cérebro, cognição e aprendizagem. São Paulo: Frôntis, 2000. 
CORDÀS, T. A. Depressão: da bile negra aos neurotransmissores: uma introdução histórica. São Paulo: Lemos, 2002.

DAMÁSIO, A. R . O erro de Descartes: emoção, razão e o cérebro humano. São Paulo: Companhia das Letras, 1996.

DESCARTES, R. Discurso do método. Lisboa: Edições 70, 1986.

ECCLES, J. C. O conhecimento do cérebro. São Paulo: Atheneu/Universidade de São Paulo, 1979.

ENGELHARDT, E. Z.; ROZENTHAL, M.; LAKS, J. Neuropsicologia II - história. Revista Brasileira de Neurologia, Rio de Janeiro, v. 31, n. 2, p. 107-113, mar./abr. 1995.

FERREIRA, A. B. H. Novo dicionário Aurélio. Rio de Janeiro: Nova Fronteira, 1986.

HEBB, D. O. The organization of behavior: a neuropsychological theory. Nova York: John Wiley, 1949.

HERCULANO-HOUZEL, S. A Frenologia e o nascimento da Neurociência Experimental. In: LENT, R. Cem bilhões de neurônios. São Paulo: Atheneu/Faperj, 2001. p. $20-21$.

KOLB, B. ; WHISHAW, I. Q. Fundamentals of human neuropsychology. 3. ed. New York: W. H. Freeman, 1990.

LEAKEY, R. A origem da espécie humana. Rio de janeiro: Rocco, 1995.

LENT, R. Cem bilhões de neurônios. São Paulo: Atheneu/Faperj, 2001.

LURIA, A. R. Fundamentos de neuropsicologia. São Paulo: Universidade de São Paulo, 1981.

MARGOTTA, R. História ilustrada da medicina. São Paulo: Manole, 1998.

OLIVEIRA, A. B. de. A evolução da medicina: até o início do século XX. São Paulo: Pioneira/Secretaria de Estado da Cultura, 1981.

SANVITO, W. L. O cérebro e suas vertentes. 2. ed. São Paulo: Roca, 1991.

SINGER, C. Uma breve história de anatomia e fisiologia desde os gregos até Harvey. Campinas: Unicamp, 1996.

SPRINGER, S. P.; DEUTSCH, G. Hemisfericidade, educação e estados alterados. In: . Cérebro esquerdo, cérebro direito. São Paulo: Summus editorial, 1998.

VYGOTSKY, L. S.; LURIA, A. R.; LEONTIEV, A. N. Linguagem, desenvolvimento e aprendizagem. São Paulo: Ícone/Universidade de São Paulo, 1988.

VYGOTSKY, L. S.; LURIA, A. R. Estudos sobre a história do comportamento: o macaco, o primitivo e a criança. Porto Alegre: Artes Médicas, 1996. 
PINHEIRO, M. Aspectos históricos da neuropsicologia: subsidios...

WALSH, K. Neuropsychology: a clinical approach. 3. ed. Edimburgo: Churchill Livingstone, 1994.

Texto recebido em 11 nov. 2004 Texto aprovado em 12 jan. 2005 